\title{
SIMMI 4.0 - A Maturity Model for Classifying the Enterprise-wide IT and Software Landscape Focusing on Industry 4.0
}

\author{
Christian Leyh \\ Technische Universität Dresden \\ Chair of Information Systems, esp. IS in \\ Manufacturing and Commerce \\ Helmholtzstr. 10, 01069 Dresden, Germany \\ Email: Christian.Leyh@tu-dresden.de \\ Katja Bley \\ Technische Universität Dresden \\ Chair of Information Systems, esp. IS in \\ Manufacturing and Commerce \\ Helmholtzstr. 10, 01069 Dresden, Germany \\ Email: Katja.Bley@tu-dresden.de
}

\author{
Thomas Schäffer \\ University of Applied Sciences Heilbronn \\ Faculty of Business Administration \\ Max-Planck-Str. 39, 74081 Heilbronn, Germany \\ Email: Thomas.Schaeffer@hs-heilbronn.de
}

\author{
Sven Forstenhäusler \\ University of Applied Sciences Heilbronn \\ Faculty of Business Administration \\ Max-Planck-Str. 39, 74081 Heilbronn, Germany \\ Email: sforsten@stud.hs-heilbronn.de
}

\begin{abstract}
The increasing digitalization of business and society leads to drastic changes within companies. Nearly all enterprises have to face enormous challenges when dealing with topics such as Industry 4.0/Industrial Internet. One of these challenges represents the realistic classification of the company's own IT infrastructure. In this paper we present a maturity model (SIMMI 4.0 - System Integration Maturity Model Industry 4.0) that enables a company to classify its IT system landscape with focus on Industry 4.0 requirements. SIMMI 4.0 consists of 5 stages. Each describes several characteristics of digitization, which allows a company to assess itself. Additionally, recommended activities are presented for each stage of digitization, which can enable a company to reach the next stage of maturity. We also present several possible topics for future research to improve and refine the developed maturity model.
\end{abstract}

\section{Motivation}

$\mathrm{O}$ NE of the most important challenges that companies currently face is the digitization of business processes and of the enterprise itself. They have to join in global digital networking, improve automation of individual or even all business processes, and reengineer existing business models to gain momentum in digital innovation. It has never been more important for enterprises to be able to rely on ITenabled capabilities, as well as to count on a deep understanding of information technology in general and in digital innovation in particular. Without a doubt, nearly all enterprises have to undergo an increasing digital transformation to remain competitive in global markets. In these efforts, the specific challenge for companies is to realize the increasing integration of virtual, digital programs with real objects or products in their everyday business in order to subsequently adapt, enhance, or optimize the processes [1]-[4].

For a while, trends such as Industry 4.0/Industrial Internet affected mainly large companies, especially since small- and medium-sized enterprises (SMEs) often judged such topics as too complex and expensive and partially classified them as not relevant. However, digitization is no longer limited to large companies and does not only concern separate functional areas such as the IT department. Rather, it takes place throughout the entire value chain of all companies [5]. Overall, together with this increasing digitalization of companies, the definitions of value-adding and supportive processes become vague, whereby the traditional supply chain of a company with its downstream processes develops into a holistic supply/value network. Thus, also SMEs open themselves for the complex topic of Industry 4.0 and try to reshape their business processes and business models in this direction. To face up to this development the use of adequate information and communication technology (ICT) is essential. However, what is missing at this point is the companies' level of knowledge concerning their own digitization. A number of studies already exist applying to this topic (e.g., [6], [7]). By using various interrogation techniques, the authors figure out which information and enterprise systems are used in business (especially in SMEs) and in what shape the IT-infrastructure of the company appears. There is, however, the question of how an IT landscape must be designed so that a company can "move" in the field of Industry 4.0. Recognizing and evaluating what systems are needed, and in which way and for what purpose, still embodies a challenge for companies.

This is where the present paper comes and this results in the main research question for our research:

What should a maturity model look like to assess a company's IT system landscape in the context of Industry 4.0?

Industry 4.0 , as the fourth stage of the industrial revolution is entitled, consists of an increasing digitization of products and systems, together with their interconnectedness. Thereby, the physical world is connected to the virtual world. The characteristics of Industry 4.0 are: e.g., horizontal integration across whole value networks, strong vertical integration within the company, and a digital 
transparency of the engineering across the entire value chain [8], [9]. However, a universal definition for the term "Industry 4.0" does not exist. From the aforementioned descriptions and further characteristics of Industry 4.0 we deduce a working definition as the foundation for our research:

Industry 4.0 describes the transition from centralized production towards one that is very flexible and selfcontrolled. Within this production the products and all affected systems, as well as all process steps of the engineering, are digitized and interconnected to share and pass information and to distribute this along the vertical and the horizontal value chains, and even beyond that in extensive value networks.

To answer the research question we present a tool (a maturity model) that enables companies to classify their own provided IT system landscape in the needs of an Industry 4.0 system landscape. This is also the core of our paper. We describe the components (dimensions and stages) of "SIMMI 4.0" (System Integration Maturity Model Industry 4.0) necessary to fulfill the requirements of an Industry 4.0 environment. Afterwards we finish with a short summary and an outlook for future research in this field.

Furthermore, related work with detailed insight into the field of Industry 4.0, as well as in the field of existing maturity models and into the development of our maturity model "SIMMI 4.0" are given in [10].

\section{SIMMI 4.0 - SYSTEM INTEGRATION MATURITY MODEL INDUSTRY 4.0}

As a starting point for model development, a further literature analysis was conducted. Contrary to the related work literature analysis in [10], the aim of this analysis was to gain an understanding about the existing level of knowledge about Industry 4.0, and, therefore, to deduce the essential requirements for IT systems in the context of Industry 4.0. Several databases (e.g., EBSCO, ScienceDirect, SpringerLink, and Google Scholar) were searched using the following terms and combinations of these terms: Information systems, Industry 4.0, Maturity models, Integration, Digitization, Internet of things and services, Cyber-physical systems, Value networks, IT systems, Enterprise systems, and Business information systems. Some of the resulting requirements from this literature analysis are presented as follows.

\section{A. Requirements for IT systems in the context of Industry 4.0}

In their final report about Industry 4.0, [8] highlighted three key requirements fostered by Industry 4.0 and thus should be supported by the enterprise application system landscape:

Vertical integration along the hierarchical levels of a company: While the different enterprise systems support their own tasks very well, the data of the respective systems, such as Enterprise Resource Planning (ERP) systems, Supply Chain Management (SCM) systems, Management
Information Systems (MIS), Product Life cycle Management (PLM) systems, etc., is often stored in separate databases (sometimes data interfaces are provided) and partly stored in different formats. This sub-optimal level of integration must be improved for implementing Industry 4.0 business processes and activities.

Horizontal integration across value networks: For the implementation and use of different enterprise systems, failures and leakages throughout the flow of information must be avoided. In fact, the information must be accessible and useable at the right time in the right "place" along the entire supply chain and therefore for all business partners. Furthermore, the exchange of such information flows must be (completely) automatized.

Digital continuity of engineering: This means supporting a product's engineering consistently and continuously along the entire supply chain by using adequate and appropriate enterprise systems and includes the production system development process as well.

Also, stemming from the literature review (especially from analyzed study results), cross-sectional technologies were identifiable as an important part of the enterprise systems. These technologies are defined below and their relevance to Industry 4.0 will be explained:

Service-oriented architecture: For example, the project "Platform Industry 4.0" has published a whitepaper that names the development of a reference architecture based on a Service-oriented architecture (SOA) as an important prerequisite for the implementation of Industry 4.0 [11].

Cloud Computing: Industry 4.0 not only leads to a digitization of separate production facilities, but also that of the enterprise's information technology at the production plant(s) as well as all companies digitally interconnected along the supply chain. Considering cloud computing, these aspects are provided as different services; therefore, this could help enterprises operate in the field of Industry 4.0 effectively and efficiently.

Information aggregation and processing: In this context, aggregation of information implies that data can be easily identified from various integrated enterprise systems through different ways of treatment, such as clustering, filtering, and correlation. In a next step, this data is made available to every user or machine that needs it. This illustrates not only that the data of the production floor/of the production systems (e.g., various interconnected machines, (semi-) products, sensors etc.) is aggregated and transferred towards the company's higher levels and enterprise systems (e.g., ERP systems, SCM systems), but also that the data needs to be transferred in the opposite direction to the production floor [12].

IT security: In Industry 4.0, the company will be connected with/to the internet not just at an operational or higher level. 
As part of the Internet of things and services, the production level/production floor, maybe even the control level of several machines themselves, as well as all levels up to the strategic level of companies will be connected through a continuous link to the internet. For this reason, IT security will be a major challenge for establishing different kinds of IT systems. Here, IT security is defined as adequate protection of all information available in form of electronic data. In addition, it must be ensured that the IT systems themselves and their services are available at all times for the users and work properly [13], [14].

\section{B. Components of SIMMI 4.0}

Depending on its aims and strategic positions as well as on its arrangements in terms of Industry 4.0, not every company needs to fully implement all the dimensions of SIMMI 4.0. There are several gradations per dimension, which in turn result in different stages within the maturity model. These dimensions can have different characteristics in terms of scope and intensity for each company. Therefore, Table I in the Appendix gives a summary of our proposal for SIMMI 4.0. In the following chapters, the dimensions and stages of SIMMI 4.0 are described in detail.

\section{B.1 Dimensions of SIMMI 4.0}

Several dimensions of the development of SIMMI 4.0 are deduced from the requirements from our literature analysis. With these dimensions, SIMMI 4.0 can enable a company to assess its IT system landscape.

Dimension - Vertical integration: This dimension focuses on the components of the lowest level of an enterprise, where different physical things ((semi-) products, machines, etc.) need to exchange information throughout the level itself and with the levels above. The most important criterion here is that this exchange is possible in both directions.

Dimension - Horizontal integration: Industry 4.0 requires horizontal integration across the different value networks. Accordingly, an essential criterion has emerged from the requirements above. An automated and integrated information flow is necessary along the horizontal enterprise level as well as beyond the enterprise borders. Without this information flow, a business-wide value network is not realizable, meaning that the various enterprise systems of the different partners in the value networks require interoperability at the data level. Therefore, a continuous and consistent information flow is needed [15], [16].

Dimension - Digital product development: For the engineering's digital continuity it is especially important that each process step is represented digitally. For this purpose, at least one enterprise system should be integrated into each respective process step. In addition, the resulting data and information of each step must be forwarded to the next and previous step/enterprise system.
Dimension - Cross-sectional technology criteria: This dimension focuses on assessing the extent to which technologies are used across all different fields of Industry 4.0. Based on the requirements, the respective fields are: Service-oriented architecture, Cloud computing, Big Data, and IT Security. In addition, the level of support that enterprise systems can provide for these fields should be evaluated in this dimension.

\section{B.2 Stages of SIMMI 4.0}

SIMMI 4.0 is divided into five stages. Additionally, key activities for each stage, which must be conducted in order to be able to achieve a higher stage, are briefly specified.

This five-stage division is justified by the fact that in the middle of this stage-model, in the third stage, the implementation of an intelligent factory (Smart factory) is completed. This foundation for Industry 4.0 should be and must be implemented in each company before stable, robust, and versatile value networks can be realized. By implementing an intelligent factory, a company can gain operating experience before the company and its systems are connected to other companies [15].

Stage 1 - Basic digitization level:

The company has not addressed Industry 4.0. Requirements are not or only partially met.

The enterprise systems along the enterprise's value chain support only their respective fields of activity. When integration is achieved, it is with specially implemented and complex interfaces. In addition, the processes are not or are only partially digitized. Product prototypes are designed in a costly way because of product development activities are not digitized. The company does not pursue service-oriented and cloud-based approaches.

The data of the enterprise systems are aggregated only for strategic decisions. In addition, the confidentiality of the data is not provided. The company's data is not protected against industrial espionage for example, incurring enormous damage annually. Anytime and continuous availability of data is not ensured. Sometimes, users cannot receive the data when they request it or access is not provided.

Activities:

- Start of engagement with focus on Industry 4.0

- First explorations of service-oriented approaches

Stage 2 - Cross-departmental digitization:

The company is actively engaged with Industry 4.0 topics. Digitization has been implemented across departments, and the first Industry 4.0 requirements have been implemented throughout the company.

Information can be (partially) exchanged automatically among different departments and business areas. This level of integration no longer contains data islands within the company. In addition, several production plants are connected but instead through cloud solutions they are 
connected through the exchange of information in other ways (paper-based, email, FTP, etc.). Production and product development is supported by several enterprise systems. However, data and information exchange is not automatized. Therefore, the previous and following steps are not optimized. The company starts to implement an SOA. Legacy systems are broken down, and their functionalities are encapsulated into services. New systems are implemented directly following the SOA principles. Thus, initial processes can be built as services. In addition, an enterprise service bus (ESB) is implemented to replace enterprise application integration principles and to enable direct connection between new systems.

\section{Activities:}

- Implementing an SOA

- Achieving cross-departmental integration

- First approaches for an IT security model

- First developments of mobile applications

\section{Stage 3 - Horizontal and vertical digitization:}

The company is horizontally and vertically digitized. The requirements of Industry 4.0 have been implemented within the company, and information flows have been automated. The product development is consistently supported by enterprise systems. Information from the respective process steps can be forwarded to the next or previous process step. The company has established an SOA. All the functionalities of the integrated systems are provided as services. The (semi-) products are part of this SOA and provide services themselves.

To exchange information within the enterprise, cloud principles are applied. Services are available company-wide and can be accessed anywhere. Employees are able to retrieve information everywhere through mobile devices. In addition, machines and (semi-) products are displayed on the mobile devices as soon as they come into the device's range. With this feature, the devices can display additional information about the machines (e.g., current processing step, maintenance status, etc.).

Various data from the production plants will be aggregated and processed together. Using this data and information gained from production, production itself can be optimized in real time and can be adapted to prevailing or changing conditions when necessary.

IT security is increased through the use of an advanced security model. Access to data is continuously protected, and data is transmitted in an encrypted state within the enterprise. The data's confidentiality, availability, and integrity are completely guaranteed.

Activities:

- Connection with other companies to build value networks

- Development of a cloud-based platform to offer services across the company border

\section{Stage 4 - Full digitization:}

The company has been completely digitized, even beyond corporate borders, and integrated into value networks. Industry 4.0 approaches are actively followed and anchored within the corporate strategy.

Consequently, the level of integration can be described as enterprise-wide and cross-corporate horizontal and vertical integration. In order to optimize processes, the product development steps automatically pass information to previous and following production steps.

The company has established a service-oriented and cloudbased platform that offers services in the value network in order to exchange information along the supply chain in real time. Machines can be maintained globally, regardless of their location (in terms of their software). Data is aggregated and processed company-wide as well as provided via entire value networks. The production floor in general is at a highly optimized level.

In addition to enterprise-wide data encryption, encryption is also used within the value networks. Users can access data anywhere by using established authentication measures.

\section{Activities:}

- Beginning collaborations with companies within the value networks for end-to-end solutions and the optimization of information flows

\section{Stage 5 - Optimized full digitization:}

The company is a showcase for Industry 4.0 activities. It collaborates strongly with its business partners and therefore optimizes its value networks. Through these collaborations, new business models and new end-to-end solutions are developed and enabled. During this development process each step inside and outside the company is digitized.

Within the value networks physical value and information flows can also be represented digitally, so the entire added value can be simulated in real time. Thus, it is possible to automatically perform necessary adjustments for all companies of the value network.

Furthermore, the IT security adjusts promptly to new risks. Occurring security problems are immediately solved. Encryption is optimized in cooperation with the partners the along the value networks.

\section{SUMMARY AND FUTURE ASPECTS}

The aim of our research is to provide a maturity model for the classification of a company's IT system landscape in the context of the Industry 4.0 requirements. Through a systematic literature review [10], we could demonstrate that no maturity model currently exists that meets the needs of Industry 4.0 in terms of a company-wide and even a crosscorporate IT system landscape. However, due to the drastic changes produced by the digitalization of businesses and society itself, it becomes necessary for enterprises to assess their IT system landscape in a realistic way. Therefore, an 
easy-to-handle tool could provide adequate support for assessment.

With this in mind, we designed a new maturity model (SIMMI 4.0 - System Integration Maturity Model Industry 4.0) for assessing the readiness of a company's IT system landscape in terms of Industry 4.0. However, this design process is not described in detail in this paper but can be found in [10].

Within this paper we present the first version of our maturity model SIMMI 4.0. Thus, the model's development is not yet fully complete. The next steps include: (1) conducting several expert interviews and model adjustments based on the interviews if necessary (2nd iteration); (2) group interviews with companies to test the model's practicability (3rd iteration). After these steps, evaluation of the maturity model will follow. This should be based on the concrete application of the model within several companies. The resulting design decisions based on the iteration steps, the transfer and evaluation in terms of the model's dimensions and stages, more detailed evaluation steps, and the model's scientific as well as practical contributions will be addressed in subsequent papers.

Beyond the development of SIMMI 4.0 (here primarily based on the literature review in [10], the comparison of existing maturity models), we identified additional links and needs for further research. For example, some maturity models already exist for the field of Industry 4.0 that deal with organizational aspects or system-specific aspects in detail. A mapping of these maturity models would be necessary to combine their different points of view. For example, different maturity level assignments and dimensions between these models should be developed to enable companies to fully classify themselves in terms of Industry 4.0 requirements in all levels of their enterprise. With this work, companies would be able to determine their overall maturity in the field of Industry 4.0.

A further aspect to investigate in the future is the data quality within various enterprise systems along the supply chain. Since companies in an Industry 4.0 environment must exchange data in large amounts and on an automated basis, a certain data quality is necessary to ensure efficient company-wide and cross-corporate business processes. Therefore, those companies should implement adequate master data management and data quality management. On this topic, two questions arise: (1) What design elements and components should be part of master data management and data quality management in the context of Industry 4.0? (2) How can master data management be integrated in maturity models addressing the IT systems landscape of Industry 4.0 companies? We will address those two questions in further research projects.

To conclude this contribution, some limitations must be recognized. Currently, SIMMI 4.0 has not been evaluated or tested. It is a maturity model that was derived from the literature by combining aspects of IT-related maturity models with Industry 4.0 requirements. In this respect, the development process of SIMMI 4.0 must continue. In the next iteration steps, we will clarify and review the model's components based on expert and company assessment. Additionally, SIMMI 4.0 must prove its practicability and usefulness in an enterprise environment. We will address both aspects of the model's limitations in our research project's future steps focusing the field of Industry 4.0.

\section{REFERENCES}

[1] M. Pagani, "Digital Business Strategy and Value Creation: Framing the Dynamic Cycle of Control Points," MIS Q., vol. 37, no. 2, pp. 617-632, 2013.

[2] D. Straub and R. Watson, "Transformational Issues in Researching IS and Net-Enabled Organizations," Inf. Syst. Res., vol. 12, no. 4, pp. 337-345, 2001. doi: 10.1287/isre.12.4.337.9706.

[3] B. Wheeler, "NEBIC: A Dynamic Capabilities Theory for Assessing Net-Enablement," Inf. Syst. Res., vol. 13, no. 2, pp. 125-146, 2002. doi: 10.1287/isre.13.2.125.89.

[4] J. Schlick, P. Stephan, M. Loskyll, and D. Lappe, "Industrie 4.0 in der praktischen Anwendung," in Industrie 4.0 in der Produktion, Automatisierung und Logistik, T. Bauernhansl, M. ten Hompel, and B. Vogel-Heuser, Eds. Wiesbaden: Springer, 2014, pp. 56-84. doi: 10.1007/978-3-658-04682-8_3.

[5] O. A. El Sawy, A. Malhotra, YoungKi Park, and P. A. Pavlou, "Seeking the Configurations of Digital Ecodynamics: It Takes Three to Tango," Inf. Syst. Res., vol. 21, no. 4, pp. 835-848, 2010. doi: 10.1287/isre.1100.0326.

[6] T. Schäffer and H. Beckmann, Trendstudie Stammdatenqualität 2013: Erhebung der aktuellen Situation zur Stammdatenqualität in Unternehmen und daraus abgeleitete Trends. Steinbeis-Edition (Schriftenreihe Wirtschaftsinformatik). Stuttgart, 2014.

[7] C. Leyh, K. Bley, and T. Schäffer, "Digitization of German Enterprises in the Production Sector - Do they know how 'digitized' they are?," in Proc. of the $22^{\text {nd }}$ Americas Conferenence on Information Systems (AMCIS 2016), 2016.

[8] H. Kagermann, W. Wahlster, and H. Helbig, Umsetzungsempfehlungen für das Zukunftsprojekt Industrie 4.0. Abschlussbericht des Arbeitskreises Industrie 4.0, Frankfurt am Main, 2013.

[9] C. Lemke and W. Brenner, Einführung in die Wirtschaftsinformatik: Band 1: Verstehen des digitalen Zeitalters, 2015th ed. Heidelberg: Springer-Verlag, 2014. doi: 10.1007/978-3-662-44065-0.

[10] C. Leyh, T. Schäffer, and S. Forstenhäusler, "SIMMI 4.0 - Vorschlag eines Reifegradmodells zur Klassifikation der unternehmensweiten Anwendungssystemlandschaft mit Fokus Industrie 4 . 0," Proc. zur Multikonferenz Wirtschaftsinformatik, pp. 1651-1662, 2016.

[11] Industrie 4.0, Industrie 4.0 - Whitepaper FuE-Themen. Veröffentlichung der Plattform Industrie 4.0 in Zusammenarbeit mit dem Wissenschaftlichen Beirat, 2014.

[12] H. Schöning and M. Dorchain, "Data Mining und Analyse," in Industrie 4.0 in Produktion, Automatisierung und Logistik, T. Bauernhansl, M. ten Hompel, and B. Vogel-Heuser, Eds. Wiesbaden: Springer, 2014, pp. 543-554. doi: 10.1007/978-3-658-04682-8_27.

[13] M. Kappes, Netzwerk-und Datensicherheit: Eine praktische Einführung, 2nd ed. Wiesbaden: Springer-Vieweg, 2013. doi: 10.1007/978-3-8348-8612-5.

[14] H. Krcmar, Einführung in das Informationsmanagement, 2nd ed. Berlin, Heidelberg: Gabler, 2015. doi: 10.1007/978-3-662-44329-3.

[15] L. Forstner and M. Dümmler, "Integrierte WertschöpfungsnetzwerkeChancen und Potenziale durch Industrie 4.0," e i Elektrotechnik und Informationstechnik, vol. 131, no. 7, pp. 199-201, 2014. doi: 10.1007/s00502-014-0224-y.

[16] D. Wegener, "Industrie 4.0 - Chancen und Herausforderungen für einen Global Player," in Industrie 4.0 in der Produktion, Automatisierung und Logistik, T. Bauernhansl, M. ten Hompel, and B. Vogel-Heuser, Eds. Wiesbaden: Springer, 2014, pp. 343-358. doi: 10.1007/978-3-658-04682-8_17. 


\section{APPENDIX}

\begin{tabular}{|c|c|c|c|}
\hline \multicolumn{2}{|c|}{$\begin{array}{c}\text { TABLE I. } \\
\text { OVERVIEW OF SIMMI 4.0 }\end{array}$} \\
\hline $\begin{array}{c}\text { Dimension } \\
\text { Vertical Integration }\end{array}$ & $\begin{array}{c}\text { Dimension } \\
\text { Horizontal } \\
\text { Integration }\end{array}$ & $\begin{array}{c}\text { Dimension } \\
\text { Digital Product } \\
\text { Development }\end{array}$ & $\begin{array}{c}\text { Dimension } \\
\text { Cross-sectional technology criteria }\end{array}$ \\
\hline
\end{tabular}

Stage 5 - Optimized full digitization:

The company is a showcase for Industry 4.0 activities. It collaborates strongly with its business partners and therefore optimizes its value networks.

\begin{tabular}{|c|c|c|c|}
\hline $\begin{array}{l}\text { Continuous cross- } \\
\text { corporate integration that } \\
\text { is constantly optimized. }\end{array}$ & $\begin{array}{l}\text { Continuous cross- } \\
\text { corporate integration } \\
\text { and collaboration in } \\
\text { value networks. }\end{array}$ & $\begin{array}{l}\text { Product development is } \\
\text { processed digitally inside and } \\
\text { outside the company } \\
\text { (digitized end-to-end } \\
\text { solution). }\end{array}$ & $\begin{array}{l}\text { Simulation and optimization of value and information } \\
\text { flows in real-time within the value network. IT security } \\
\text { adjusts promptly to new risks. Occurring security } \\
\text { problems are immediately solved. Encryption is } \\
\text { optimized along the value networks. }\end{array}$ \\
\hline
\end{tabular}

\section{Stage 4 - Full digitization:}

The company is completely digitized even beyond corporate borders and integrated into value networks. Industry 4.0 approaches are actively followed and anchored within the corporate strategy.

\begin{tabular}{l|l|l|l}
$\begin{array}{l}\text { Continuous cross- } \\
\text { corporate integration. }\end{array}$ & $\begin{array}{l}\text { Continuous cross- } \\
\text { corporate integration } \\
\text { in value networks. }\end{array}$ & $\begin{array}{l}\text { Product development } \\
\text { information are digitally } \\
\text { forwarded. }\end{array}$ & $\begin{array}{l}\text { Service-oriented cloud-based platform. Services are } \\
\text { offered for the partners in the value networks. } \\
\text { Information and data are exchanged in real-time along } \\
\text { the supply chain. Optimization of the entire production } \\
\text { through Big Data solutions. Access to data is protected. } \\
\text { Cross-corporate encryption of data and authentication } \\
\text { for global access. }\end{array}$ \\
\hline
\end{tabular}

\section{Stage 3 - Horizontal and vertical digitization:}

The company is horizontally and vertically digitized. Requirements of Industry 4.0 have been implemented within the company, and information flows have been automated.

\begin{tabular}{l|l|l|l}
$\begin{array}{l}\text { Complete } \\
\text { internal/enterprise-wide } \\
\text { integration of all } \\
\text { enterprise systems and } \\
\text { machines. }\end{array}$ & $\begin{array}{l}\text { Complete } \\
\text { internal/enterprise- } \\
\text { wide integration of all } \\
\text { enterprise systems and } \\
\text { machines. }\end{array}$ & $\begin{array}{l}\text { Product development is } \\
\text { continuously digitally } \\
\text { supported. }\end{array}$ & $\begin{array}{l}\text { SOA has been established. All functions are provided as } \\
\text { services. (Semi-) products and their functionalities are } \\
\text { available as services. To exchange information within } \\
\text { the enterprise, cloud principles are applied. Production is } \\
\text { adjusted and optimized in real-time. IT security is } \\
\text { increased through the use of an advanced security } \\
\text { model. Access to data is continuously protected, and } \\
\text { data is transmitted in an encrypted state within the } \\
\text { enterprise. }\end{array}$ \\
\hline
\end{tabular}

Stage 2 - Cross-departmental digitization:

The company is actively engaged with Industry 4.0 topics. Digitization is implemented across departments and first Industry 4.0 requirements are implemented throughout the company.

\begin{tabular}{|c|c|c|c|}
\hline $\begin{array}{l}\text { Cross-departmental } \\
\text { integration }\end{array}$ & $\begin{array}{l}\text { Cross-departmental } \\
\text { integration }\end{array}$ & $\begin{array}{l}\text { Production and product } \\
\text { development is supported by } \\
\text { several enterprise systems. } \\
\text { Data and information } \\
\text { exchange is not automatized. }\end{array}$ & $\begin{array}{l}\text { Implementation of first services (SOA with an enterprise } \\
\text { service bus (ESB)). First experience with Big Data and } \\
\text { its applications. Development of the first IT security } \\
\text { models }\end{array}$ \\
\hline \multicolumn{4}{|c|}{$\begin{array}{l}\text { Stage } 1 \text { - Basic digitization level: } \\
\text { The company has not addressed Industry 4.0. Requirements are not or only partially met }\end{array}$} \\
\hline $\begin{array}{l}\text { Integration of enterprise } \\
\text { systems only } \\
\text { departmental-specific. } \\
\text { The enterprise systems } \\
\text { along the enterprise's } \\
\text { value chain support only } \\
\text { their respective fields of } \\
\text { activity }\end{array}$ & $\begin{array}{l}\text { Integration of } \\
\text { enterprise systems } \\
\text { only departmental- } \\
\text { specific. The } \\
\text { enterprise systems } \\
\text { along the enterprise's } \\
\text { value chain support } \\
\text { only their respective } \\
\text { fields of activity }\end{array}$ & $\begin{array}{l}\text { Product development is not } \\
\text { digitally supported }\end{array}$ & $\begin{array}{l}\text { No service-oriented or cloud-based approaches. Data } \\
\text { and information flows are not used for product } \\
\text { improvement/optimization. Confidentiality, availability } \\
\text { and integrity of the data are not guaranteed. }\end{array}$ \\
\hline
\end{tabular}

